\title{
Sequential downgrading of dysplasia in ulcerative colitis using carbon dioxide-based cryotherapy
}

An 80-year old Caucasian woman with a 35-year history of left-sided ulcerative colitis (UC) underwent surveillance colonoscopy in January 2009. A random biopsy of the rectum revealed chronic colitis with low-grade dysplasia. A repeat colonoscopy in May 2009 revealed a polypoid area $3 \mathrm{~cm}$ from the anal verge with histological examination revealing low and high grade dysplasia. The patient declined colectomy and an attempt was made at local surgical excision. Biopsies revealed both low and high grade dysplasia with positive margins. The patient again refused colectomy. Two attempts were made to ablate visible dysplasia with argon plasma coagulation, but follow-up colonoscopies demonstrated recurrence including lesions at the dentate line. A novel approach utilizing carbon dioxide $\left(\mathrm{CO}_{2}\right)$-based cryotherapy (GI Supply, Camp Hill, Pennsylvania, USA) was initiated. Five treatment sessions were carried out at 8-week intervals with ablation of all dysplastic areas. At each session eight, 15-second pulses were applied. The patient reported no bleeding, diarrhea, or discomfort with the treatments. Histopathological examination revealed progressive downgrading and eventual ablation of all dysplastic mucosa (๑ Fig. 1a-c).

We believe this is the first report of successful treatment of dysplasia in UC with cryotherapy. A recent study by Xue et al. revealed that $\mathrm{CO}_{2}$-based cryotherapy was highly effective in eradicating intestinal metaplasia and low grade dysplasia in 22 subjects with Barrett's esophagus after a median of two treatments [1]. At 6 months, only 3/22 subjects exhibited recurrence of intestinal metaplasia. Similarly, Shaheen et al. reported that liquid nitrogen-based cryotherapy was successful in treating Barrett's esophagus with high grade dysplasia [2]. Rates of eradication of high grade dysplasia, low grade dysplasia, and intestinal metaplasia after a mean of four treatments were $97 \%$, $87 \%$, and $57 \%$, respectively.

Cryotherapy may be an effective treatment alternative to surgery in appropriate patients with UC (with an isolated area of dysplasia) who are poor candidates for colectomy or in those who refuse a surgical approach.

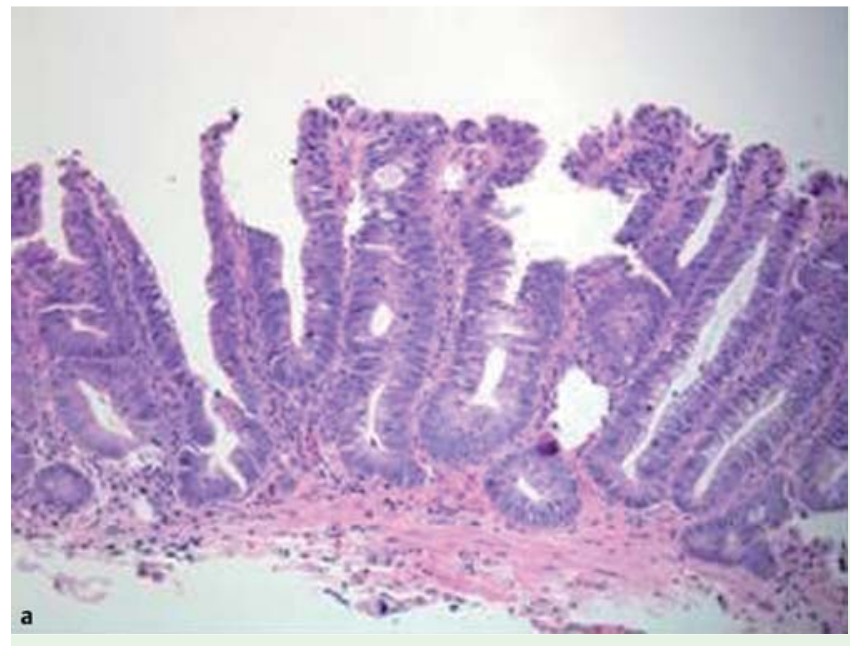

Fig. 1 Cryotherapy of dysplasia in ulcerative colitis: sequential downgrading of pathologic sections.

a Week 0 , before cryotherapy: low and focal high grade dysplasia involving all the crypts. b Week 24, after three sessions: residual low grade dysplasia is limited to two crypts (arrows), and is characterized by elongated hyperchromatic nuclei and reduced number of goblet cells. The sur-

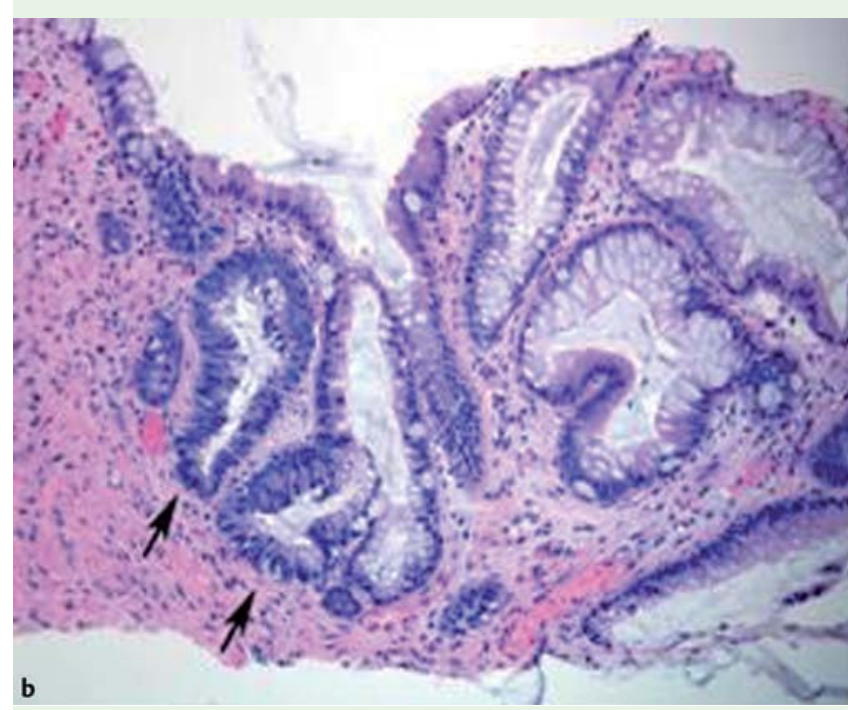
rounding rectal mucosa has low nuclear-to-cytoplasm ratio and abundant goblet cells without dysplasia. c Week 40, after five sessions: no dysplasia. Normal crypt architecture, abundant goblet cells, and small basallocated nuclei with surface maturation can be seen.

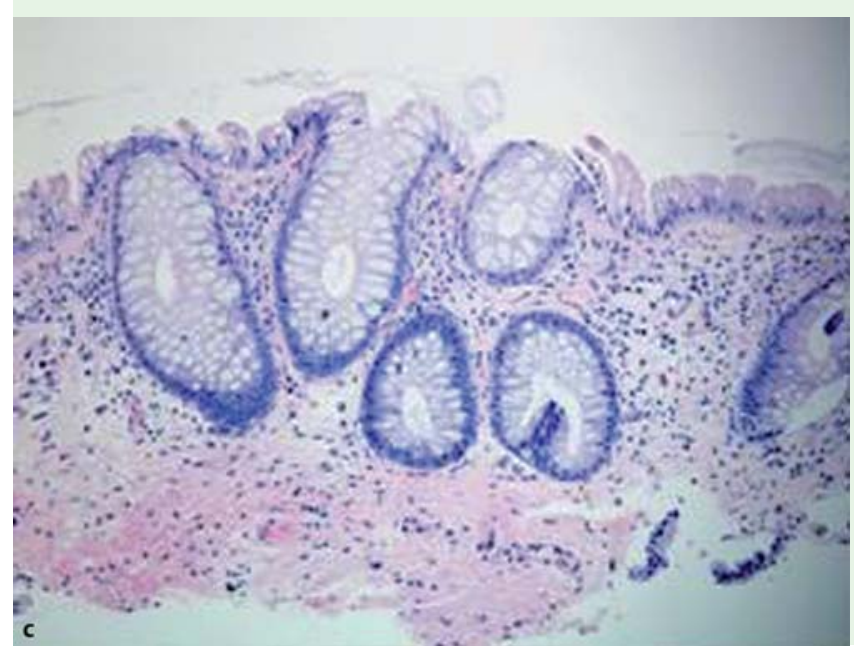


Endoscopy_UCTN_Code_TTT_1AQ_2AD

Competing interests: None

J. R. Lewis ${ }^{1}$, S. Itzkowitz' ${ }^{1}$, H. Zhu², S. C. Ward ${ }^{2}$, S. Anandasabapathy ${ }^{1}$

${ }^{1}$ Division of Gastroenterology, Mount Sinai School of Medicine, New York, USA

2 Department of Pathology, Mount Sinai School of Medicine, New York, USA

\section{References}

1 Xue HB, Tan HH, Liu WZ et al. A pilot study of endoscopic spray cryotherapy by pressurized carbon dioxide gas for Barrett's esophagus. Endoscopy 2011; 43: 379-385

2 Shaheen NJ, Greenwald BD, Peery AF et al. Safety and efficacy of endoscopic spray cryotherapy for Barrett's esophagus with highgrade dysplasia. Gastrointest Endosc 2010; 71: $680-685$

\section{Bibliography}

Dol http://dx.doi.org/ 10.1055/s-0032-1306788 Endoscopy 2012; 44: E96-E97

(c) Georg Thieme Verlag KG

Stuttgart · New York

ISSN 0013-726X

\section{Corresponding author}

J. R. Lewis

211 East 89th Street

Apartment \#C4

New York

NY 10128

USA

jeff.lewis@mountsinai.org 